Published online 2015 September 29.

Letter

\title{
Dermatological Disorders Caused by Middle East Respiratory Syndrome
}

\author{
Hai Err," and Viroj Wiwanitkit ${ }^{2}$

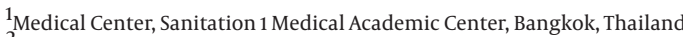 \\ ${ }^{2}$ Tropical Medicine Unit, Hainan Medical University, Haikou, China \\ ${ }^{*}$ Corresponding author: Hai Err, Medical Center, Sanitation 1 Medical Academic Center, Bangkok, Thailand. Tel: +66-892347765, Fax: +66-892347765, E-mail: haierbj@live.com
}

Received 2015 June 16; Accepted 2015 September 15.

Keywords: Dermatological Problems, Middle East Respiratory Syndrome

\section{DearEditor,}

Middle East Respiratory Syndrome (MERS) is a significant and emerging disease that has already spread from its initial origin in the Middle East to several areas around the world (1). MERS is a respiratory infection that causes acute illnesses that can rapidly lead to respiratory failure and death. There are also non-respiratory issues, such as dermatological disorders like petechiae as a result of thrombocytopenia, which can arise during cases of MERS (2). In fact, up to $36 \%$ of MERS patients have been reported to have symptoms of thrombocytopenia in the past (3). Since some cases of MERS can present mild, unrecognized, or asymptomatic cases of thrombocytopenic petechiae (4), differential diagnoses of MERS should be considered during examinations of patients with petechiae.

\section{References}

1. Joob B, Wiwanitkit V. Magnitude to thrombocytopenia among the patients with novel Middle East respiratory syndrome. Platelets. 2015;26(6):612. doi: 10.3109/09537104.2014.934796. [PubMed: 24984004]

2. Leung $\mathrm{CH}$, Gomersall $\mathrm{CD}$. Middle East respiratory syndrome. Intensive Care Med. 2014;40(7):1015-7. doi: 10.1007/s00134-0143303-y. [PubMed: 24818865]

3. Assiri A, Al-Tawfiq JA, Al-Rabeeah AA, Al-Rabiah FA, Al-Hajjar S, Al-Barrak A, et al. Epidemiological, demographic, and clinical characteristics of 47 cases of Middle East respiratory syndrome coronavirus disease from Saudi Arabia: A descriptive study. Lancet Infect Dis. 2013;13(9):752-61. doi:10.1016/S1473-3099(13)70204-4. [PubMed: 23891402]

4. Omrani AS, Matin MA, Haddad Q, Al-Nakhli D, Memish ZA, Albarrak AM. A family cluster of Middle East Respiratory Syndrome Coronavirus infections related to a likely unrecognized asymptomatic or mild case. Int J Infect Dis. 2013;17(9):e668-72. doi: 10.1016/j.ijid.2013.07.001. [PubMed: 23916548] 